\title{
Hanoi on wheels: Emerging automobility in the land of the motorbike
}

\section{Arve Hansen}

Centre for Development and the Environment, University of Oslo, Norway

Key words: automobility, moto-mobility, Vietnam, middle class, consumption, distinction, motorbike ethnography

\begin{abstract}
Vietnam's recent economic and social transformations are manifested in the streets of its capital city through millions of motorbikes and a rapidly growing presence of cars. Based on 'motorbike ethnography' in the streetscapes of Hanoi, the paper considers the changing practices and meanings of motorised mobility in Vietnam's capitalist transition. It focuses on two main aspects: the everyday geography of the 'system of moto-mobility', and the 'social life' of cars and motorbikes. The paper finds that although motorbikes still dominate in Hanoi, the car has overtaken the throne as the main aspirational and positional good, and currently automobility is becoming progressively normalised.
\end{abstract}

Word count (excluding title page, notes and references): 9980

\section{Corresponding author:}

Arve Hansen, Centre for Development and the Environment, University of Oslo, Norway, PO Box 1116 Blindern, 0317 Oslo.

Telephone: +4722858844

Email: arve.hansen@sum.uio.no 


\section{Introduction}

Driving in the streets of Hanoi can be an overwhelming experience. The intense and noisy traffic, simultaneously moving in all directions, demand constant concentration. In the densely populated city centre, street vendors, hawker stalls, pedestrians and a range of vehicles compete for scarce road space, while the smell of exhaust fumes intermingle with the multitude of fragrances from the famous Hanoian street food scene. Nevertheless, the biggest challenge for newcomers to Hanoian streetscapes, whether on foot or on wheels, is the sheer numbers of motorbikes ${ }^{1}$. The two-wheelers are seemingly everywhere, either parked or in motion, and the humming and honking of millions of motorbikes is the soundtrack of contemporary Hanoi.

While motorbikes have been present in the streets of Hanoi since colonial times, the motorbike dominance seen today is a relatively recent phenomenon, developing after Vietnam embarked on the market reforms known as doi moi in $1986 .^{2}$ Increased mobility of goods and people has been at the core of the changes in Vietnam since reforms. This has taken place on different scales, with increased flows of goods, ideas and people in and out of the country and in and out of regions within the country; increased rural-urban migration; and new forms of mobility within cities. Importantly, the flows of goods and people have also changed significantly, with integration into regional and global capitalism replacing the former networks of mobility within the communist bloc. In urban areas, doi moi has led to a significant reorganisation of urban geographies through new patterns and practices of housing, work and leisure, as well as of the forms of mobility spatially connecting these.

While a wide range of commodities have become more available in Vietnam and Hanoi the last decades (e.g. Drummond, 2012; Hansen, Nielsen and Wilhite, in press), probably none has made an impact comparable to that of the motorbike. While bicycles still dominated individual transport in the early days of reforms, the number of motorbikes started really taking off as the reforms matured (see Hansen, in press). By 1996 Vietnam was home to 4 million of them (MONRE 2007), and by the end of 2014 this number had increased more than ten-fold to an astounding 43 million motorbikes (Vietnam Register in Tuoi Tre News, 2015). In fact there are now 4 million motorbikes in Hanoi alone, close to on average two and a half motorbikes per Hanoian household (World Bank, 2014a).

The motorbikes in today's Hanoi are at least as dominant as cars are in a typical city in the mature capitalist world. In the recent decade, however, another mobility transition has become 
increasingly visible for every year I have visited the city: there are more cars on the road. Statistics confirm the impression from the streets. Since 2005 car ownership in Hanoi has more than tripled, and the city is now home to more than 200.000 cars (World Bank, 2014a). This still results in only one car per 20 motorbikes, but car ownership is growing much faster than motorbike ownership (World Bank, 2014a), and the private automobile is making strong material, social and cultural impacts.

How can we understand the persistence of motorbikes, the increasing popularity of cars, and the relations between the two means of transportation in Hanoi from a mobilities perspective? With the 'mobilities turn' or the 'new mobilities paradigm' (Sheller and Urry, 2006) maturing, the field has produced an impressive array of research. While the approaches have in common an interest in what Cresswell $(2006,2)$ has described as unpacking 'the line that links A to B', the field has produced research on highly diverse topics (see Creswell 2010, 2012, 2014 for overviews), including the meanings and moorings of basically any means of transportation (see for example the contributions in Vannini, 2011). Although aeromobilities (Adey, 2008), railway mobility (Roy and Hannam, 2013), vélomobility (McIlvenny, 2015), and walking (Middleton, 2011) have attracted attention, cars have been placed in a special position. Through work on automobilities (e.g. Sheller and Urry 2000; Urry, 2004; Featherstone 2004; Dennis \& Urry, 2009; Merriman, 2009) the previously surprisingly understudied social and material significance of the car has been thoroughly investigated, at least in mature capitalist countries (although see e.g. Edensor, 2004; Giucci, 2012; Monroe, 2014; Butler and Hannam, 2014; Broz and Habeck, 2015). Since the mobilities turn, detailed accounts have been given of aspects of automobility such as driving (Thrift, 2004), 'passengering' (Laurier et al., 2008), accidents (Short and Pinet-Peralta, 2010), and 'automotive emotions' (Sheller 2004).

The attention given to cars stands in sharp contrast to the neglect of motorbikes and motorcycles in the mobilities literature. As an example, when Urry $(2004,29)$ in his influential article on the system of automobility states that ' $[t]$ he seamlessness of the car journey makes other modes of travel inflexible and fragmented', this clearly overlooks twowheeled motorised transport. Pinch and Reimer's (2012) discussion of 'moto-mobility' is thus a welcome contribution. Still, their analysis focuses on the motorcycle as a form of alternative mobility in a car dominated system. Indeed, as argued by Gillen (2015), when motorbikes do enter mobility discussions, it tends to be as an 'exotic' means of travel in usually wealthy, English-speaking countries. The crucial role played by motorbikes in the everyday mobilities 
of a range of countries, particularly in Eastern parts of Asia but increasingly also elsewhere (such as in many African countries), thus remains seriously understudied.

This paper first of all aims to understand the everyday geography of Hanoi's motorbikedriven society. As Hansen (2015b) argues, in Hanoi the dominance of motorbikes has materialised through the interplay of factors such as everyday practices, industrialisation, regional integration, increasing affluence, and existing urban two-wheeled infrastructure. This paper builds on these insights, and drawing on my own 'motorbike ethnography' and on Urry's (2004) system of automobility argues that a local 'system of moto-mobility' is discernible in Hanoi. The second aim of this paper is to explore why and how automobility emerges in such a system. Hansen (2015b) argues that in an already 'motorised' society, the increasing popularity of cars stems from how cars allow for practices of mobility to be performed in a safer, more comfortable, cleaner and 'healthier' manner, all the time allowing the driver to display social status while being mobile. This article elaborates on the latter point, and analyses the 'social life' (Appadurai, 1986) of cars and motorbikes in Hanoi's streetscapes, as well as how this in addition to depending on material affluence and mobility of goods is moored in socio-cultural changes following Vietnam's capitalist transition. By 'putting social relations into travel' (Sheller and Urry, 2006: 208), I introduce the concept of 'mobile distinction' to explain a central part of automobility in contemporary Hanoi. The paper thus sheds light on both an understudied phenomenon in the rapid development of Vietnam $^{3}$ and brings research on automobility and moto-mobility out of their usual cardominated contexts and streetscapes.

Towards the end of the paper I discuss the normalisation of cars in Hanoi, before briefly considering to what extent Vietnam and Hanoi's mobility developments are exceptional in comparison to other countries in the region. First of all, however, I briefly introduce the methodology that has played a crucial role in shaping my interpretation of Hanoian mobilities.

\section{Methodology: 'Motorbike ethnography'}

The research behind this paper is based on both mobile and immobile qualitative methods (Merriman, 2014). Inspired by mobile methods' aim to 'go along with' the movements of the contemporary world in order to better grasp it (Büscher, Urry, and Witchger 2011), I have been on the move and in traffic much of my fieldwork. More specifically, the fieldwork has 
been 'moto-mobile', as for the great majority of time I drove a motorbike. This allowed me to participate in the life of Hanoi traffic, to visit widely different parts of the city, and to mentally and bodily experience both the pleasures and dangers of moto-mobility. ${ }^{4}$ It furthermore provided me the opportunity to gain first-hand experience of the logics of Hanoian moto-mobility, as well as the impact of the growing number of cars in the streets.

The fieldwork in Hanoi was conducted over a total of seven months in 2012 and 2013. In addition to the participative approach of observing-while-being-in traffic, the fieldwork also consisted of more immobile interviews, usually conducted in offices or coffee shops (usually reached by motorbike). This included semi-structured and in-depth interviews with a number of policy makers, car and motorbike retailers, car and motorbike manufacturers, and, most importantly, 30 car owners and 16 motorbike owners. The car- and motorbike-owning group of informants mainly belonged to what broadly can be described as the middle class in Vietnam, although their incomes ranged from average to very high. In addition this research has benefitted from a very large number of informal talks about cars and motorbikes with people all over Vietnam, as well as car journeys (as a passenger) and motorbike rides in many different parts of the country, rural and urban, during numerous visits since 2010. The informants were chosen mainly through snowball sampling, based on the networks of informants, colleagues, acquaintances, and different research assistants. Within this snowball approach, the main sampling strategy was to encounter informants with different backgrounds and occupations and of different age and gender. My informants came from a wide range of occupations and social positions, such as teachers, clerks, military officials, state-employed academic researchers, a variety of businessmen and -women, and government officials of different ranks, including family members of very high ranking officials.

\section{Hanoi on wheels: The system of moto-mobility and its everyday geography}

While demanding significantly less energy, resources and road and parking space than the car, the ways the motorbike has become embedded in the material and social life of Hanoi share many similarities with the role of the car in Urry's (2004) system of automobility. According to Urry (2004), automobility as a concept refers to a 'self-expanding' system whose broader social, cultural and material interlinkages fundamentally shape modern life. Automobility can further be conceptualised as a 'self-organizing autopoietic, non-linear system that spreads world-wide, and includes cars, car-drivers, roads, petroleum supplies and many novel objects, 
technologies and signs' Urry $(2004,27)$. I will not speculate to what extent the system of moto-mobility should be considered as self-expanding, nor will I focus on how or whether it is expanding globally ${ }^{5}$, but will rather analyse the local materialisation of a mobility system. The social, cultural and material interlinkages of moto-mobility have fundamentally shaped Hanoi, from infrastructure through consumption geography to everyday practices (see Hansen, 2015b). And just like Urry describes the car-driver, the motorbike-rider can usefully be conceptualised as a 'hybrid assemblage of specific human activities, machines, roads, buildings, signs and cultures of mobility' (Urry, 2004, 26). In order to understand how these assemblages and interlinkages work in practice, I hold that the best approach is to engage in mobile practices to ground new knowledge in the particularities of the many different spaces and places of mobility.

\section{Driving in the system of moto-mobility}

A typical day for a large number of Hanoians starts in a mobile fashion by getting up early (often around $5 \mathrm{am}$ ) and head out for the morning exercise. This is a special time of day in the city, where Hanoi can remind of the stories and pictures of the 'old days' when the streets were tranquil and people were using their feet or bicycles to get around town. All around the city people are walking, bicycling or practicing tai chi, or they are in public squares such as Ly Thai To or by the Lenin monument participating in more organised activities such as dancing, aerobics, or even 'laughing yoga'. The city is very much alive, and mobile street vendors on foot or bicycles are offering a range of goods by the streets. Following the morning exercise it is time for breakfast, either at home or at a favourite pho place, perhaps followed by a coffee with friends (particularly for men) or (usually for women) a walk or bicycle ride to the local wet market to try to agree on prices with the vendors for the daily quanta of fresh produce. Around 7 am the streetscapes start changing into the particular scenes that are now iconic for Hanoi and Vietnam. Millions of Hanoians bring their motorbikes out of their living rooms or other parking areas and enter the streets. These motorbikes and their riders, together with the systems of provision and the infrastructure that has dialectically developed alongside them, as well as the particular socialities they enable and reinforce, make up what I consider a local system of moto-mobility.

Watching the flow of these two-wheeled human-machine hybrids from the side-line is fascinating, and evokes images of chaos. This is the chaos that has made Hanoi highly 
unfriendly to non-motorised transport. Motorbikes can go almost anywhere, and are found in every nook and cranny of the complex two-wheeled friendly system of labyrinths in Hanoi. ${ }^{6}$ They are usually parked - in rush hours even driven - on the sidewalks, to the detriment of pedestrians and cyclists (see Leather et al. 2011). The system of moto-mobility provides a rather unique sense of urban mobility that I would argue extends far beyond that of the car in the system of automobility. This mobility is almost addictive, allowing motorbikers to relatively easily move from doorstep to doorstep more or less anywhere in the densely populated city, and in many different ways make walking a little tempting option. As put by Vietnamese novelist Nguyen Truong Quy (2014, 21): 'Such is the Hanoian's attachment to the motorbike that these days, using one's feet has become an option of last resort, the little chore one must suffer when arriving at the office or walking into one's home'. At the same time, in a context where public transport has not kept up with rapid urbanisation, the motorbike has been the saviour for getting Hanoians around town in a new economy requiring increased spatial mobility (World Bank, 2011).

The at first glance unruly streetscapes can be terrifying for newcomers, as the many online tourist guides on how to cross the street in Hanoi testifies to. But enter the streets on your own motorbike and become part of the swarm, and you soon notice the logics of traffic. Nguyen Truong Quy $(2014,67)$ has caught well how the frenzied traffic changes when you become part of the movement: 'when I am in that sea myself, there's no problem, I am in my element, flowing and coursing with the ease of a fish in water'. This reflects my own experiences in my many daily drives in the city, where I would soon adapt to the swarms around me, even to the point of driving on sidewalks when in a rush to get somewhere. In the mostly narrow streets, traffic jams certainly also occur, something that I quickly discovered in my daily commute to my Hanoi office, although far from the extent of other large Southeast Asian cities where car ownership is more widespread, such as downtown Bangkok or the infamous macet in Jakarta. Requiring significantly less space, the hordes of motorbikes flow in very different ways from the typical stagnant traffic jam of cars, although becoming part of the individual yet collective movement of these bikes still strongly shapes your own movements in traffic.

\section{The particularities of Hanoi's moto-mobile streetscapes}

I could easily spend the whole paper discussing the different norms and practices in Hanoian traffic, ranging from frequently driving on the wrong side of the road through the art of 
dodging pedestrians to the many particularities of honking (honk too little and you represent danger in traffic, honk too much and you are deemed as uncivilized). Some practices, like the fact that a majority of motorbikers at traffic lights start driving some seconds before the red light changes to green and stop driving some seconds after it has changed to red again add chaos, materially moored in the countdown system displayed on all traffic lights in the city. Seemingly everyone disobeys some of the formal rules of traffic, but if you diverge too much from the normal, accepted behaviour, for instance by ignoring red lights completely or honking constantly as you drive (a surprisingly common practice), you are quickly judged as lacking urban know-how. Many of my middle-class informants indeed blamed the traffic situation in Hanoi on people being uneducated, and particularly on the many rural migrants in the city. Break the law, and you also risk running into the traffic police. In central Hanoi the traffic police in their khaki uniforms are apparently everywhere, ready to hand out fines for any minor or major offence, usually solved through a 200.000 Vietnamese Dong (VND) ${ }^{7}$ 'direct payment' (read: bribe) ${ }^{8}$.

While more unconventional vehicles such as oxcarts, tuktuks, and cyclos have been banned from the streets of Hanoi (the latter are still allowed for tourism purposes), the motorbikes have almost completely taken over the city. However, young people on electric bicycles and, increasingly, electric scooters, silently glide past you, their quiet engines disrupting traditional traffic practices of navigating by sound. While holding a certain elusive promise of greener mobility, the electric bicycles, not requiring helmet nor a driver's license to operate, so far seems to compete more with the traditional bicycles than with motorbikes. The few remaining bicycles in the streets are either the often Vietnamese made bicycles of school children, the rackety old bikes of street vendors, the colourful 'fixie bikes' of the young and trendy or the expensive, imported mountain bikes now in fashion for exercise among the better off.

Motorbikes come in all shapes and sizes, but are usually small and light. The motorbike models are in many ways gendered, men traditionally preferring 'semi-automatic' versions where you place one leg on each side of the bike and do your own gearing, while models aimed towards the female market segment are usually the more petrol-consuming fully automatic scooters designed to let the driver keep the legs together (thus being skirt-friendly). In addition, new models such as Honda's 'Lead', despite being quite large and heavy, have become very popular partly because of the generous space under the seat. Many of my female informants reported this feature as highly convenient as it allowed them to store for example purses while driving, and helmets and 'driving gear' while parked. The latter is another 
common sight in Hanoi's streets and a central part of the material culture of Vietnamese moto-mobility; girls and women covered from head to toe in clothing designed to keep the sun out and the skin pale.

Larger motorcycles demand special permission, which interestingly usually has required membership in a motorcycle club, and are seldom seen in the streets. Rare are also the few remaining left-over motorbikes from the former communist bloc, such as the famous Minsk and Babetta. Those that dominate traffic range from the early Honda motorbikes such as the 'Dream' through contemporary Japanese and Taiwanese models to more exclusive scooters of Italian making. Motorbikes also function as taxis. Although the number of taxi cabs have grown so rapidly that Hanoi stopped granting new licenses in 2012 (Thanh Nien News, 2014), still all over the city xe om drivers (motorbike taxis, literally 'hugging vehicle') are waiting and shouting for customers on the street corners, often in impressive manners taking a nap on their parked motorbikes. ${ }^{9}$

\section{Mundane mobilites and their moorings}

As noted in the introduction, two-wheeled motorised mobility has in the literature mainly been approached through subcultures and alternative mobilities, visible in for example the contributions to the Journal of Motorcycle Studies. This diverges significantly from the position of motorbikes in Hanoi, although of course some Hanoians are quite passionate about their bikes. The motorbike mainly represents the normal way to perform mundane mobilities. In short time it has become an essential part of the highly mobile Hanoian everyday life, and is used for all kinds of purposes, such as carrying out errands, going to work or school and home or to restaurants for lunch, picking up children, or even 'walking' the dog, in turn making Hanoian everyday practices highly motorised.

Aldred and Jungnickel $(2013,606)$ have described the car as 'an object whose ownership and use both enables and locks in a variety of practices'. In Hanoi the car also locks out some of the old practices of the motorbike, such as driving from doorstep to doorstep, or stopping alongside the road to shop, eat or drink. And the narrow streets and large networks of alleyways make the city much easier to traverse on two wheels than on four (Hansen, 2015b). In other words, the system of moto-mobility makes the car in many ways an inconvenient means of transportation. 
In the literature on automobility, the possibility to individually decide when and where to move is often considered one of the main allures of the car. In the words of Sheller and Urry (2000, 743),

Automobility (in some respects) is a source of freedom, the "freedom of the road". Its flexibility enables the car-driver to travel at speed, at any time, in any direction along the complex road systems of western societies that link together most houses, workplaces and leisure sites. Cars, therefore, extend where people can go and hence what as humans they are literally able to do.

Inside Hanoi, this 'freedom' is arguably more the case for motorbikes than cars. In the words of a young, female motorbike driver, 'the best part of driving a motorbike is [that] you take freedom in your own hands and can go anywhere you want' (Interview, October 2013). The motorbike provides a highly flexible, privatised means of getting around. Indeed it has been closely associated with the new post-reform freedoms of Vietnam (Truitt, 2008). However, as Urry's (2004) has characterised the system of automobility, this is in many ways a coerced flexibility, as the lack of public transport combined with the structuring of everyday life and the urban environment of Hanoi around the two wheeler frequently leaves Hanoians with little choice.

Cerise and Maximy (2010) aptly describe the streets of Hanoi as inhabited by a population of 'centaurs', so closely attached to the motorbike that it can almost be seen as a part of their bodies. Driving it has in turn become 'second nature' to Hanoians, according to Nguyen Truong Quy $(2014,20)$. It feels so 'natural' to drive that many of my informants told me they started driving one long before they had turned 18 (the required age by law), and very few of them reported to have driver's licenses. Indeed, Mai Ha (2014) has suggested less than 4 percent of Vietnam's inhabitants hold a driver's license, despite the fact that on average every household nationwide owns a motorbike (GSO, 2012). Again this separates motorbikes from cars. All of my car-owning informants had driver's licenses, and many reported driving a car as quite challenging. While driving a motorbike in Hanoi certainly requires quite some skills, it seems to in relatively short time have undergone a process of social normalisation to the extent that driving one is almost perceived as an integral part of being Vietnamese; a young, female motorbike owner indeed compared riding a motorbike for Vietnamese to riding a horse for Mongolians (Interview, October 2013). 
The system of moto-mobility also depends on its own set of moorings. A crucial part is played by the narrow road networks and housing practices (see Hansen, 2015b), but also by the parking infrastructure. Very different from the eternal search for parking space often associated with urban automobility, parking a motorbike in Hanoi is rarely a problem. At home, motorbikes are usually parked on the front porch at daytime and inside, often in the living room, at night time. In public spaces, motorbikes are parked on the sidewalks, usually immediately in front of shops, offices are other businesses, and are often watched by a parking attendant who will usually write a number in chalk on the seat of your motorbike and hand you a note with your designated number. Others will organise the parked motorbikes by license plate, and Hanoians will often memorise the digits of their license plates. The organised parking facilities all have in common that they charge around 5.000 VND for parking, no matter how long you leave it there (as a foreigner, the price may easily be higher!). In addition, many are running private businesses by letting people park their bikes in private parking lots. Normally, however, you will never have to walk very far. The new malls that have been popping up in different areas of the city use a similar but more modernised parking system, often involving electronic cards (without any chalk-scribbling on the seat). The parking facilities of these malls are usually found in the basement, where often thousands of motorbikes are lined up, in many places organised according to brand (for example the Vespas in one area, Hondas in another). Cars are on different floors, and the ample room for car parking in the new malls separates them from the conspicuous lack of parking space for cars in central Hanoi, and can be seen as both a response to and expectation of emerging automobility.

\section{Emerging automobility}

Driving a motorbike in the streets of Hanoi, you very quickly notice the cars. Despite still being outnumbered by motorbikes, the cars have started to make substantial impact. A car requires up to seven times the road space of a motorbike (World Bank, 2014b), and in the narrow streets designed for two-wheelers, cars easily clog up traffic. They struggle to push their way through the sea of motorbikes, and although useful as 'shields' against traffic at intersections, cars make traffic more dangerous for the more vulnerable motorbike drivers. Striking is also the prevalence of new and expensive cars, moored partly in the high prices on 
any cars and the limited access to used cars and, as discussed below, partly in more symbolic concerns.

Due to high levels of taxes and fees, a car in Vietnam is relatively speaking very expensive. Although it may be possible to acquire a used car for 200-300 million VND, a new car usually starts at more than 500 million. A new Toyota, one of the most popular brands in Hanoi, will often cost closer to 1 billion. By comparison, a new Honda motorbike is available for less than 20 million VND (although the most expensive Piaggio models cost several hundred million). Furthermore, the expenses for parking, insurance, fuel and fees among my car owning informants varied between 3 and 10 million VND a month. With a job in the public sector, an individual will usually (officially) earn somewhere between 3 and 5 million a month. A farmer or construction worker earns less. A car is thus far out of reach with a 'normal' income, and it is safe to assume that a car owner belongs to Hanoi's upper echelons. In this sense cars are a mobile manifestation of the inequalities embedded in Vietnam's capitalist transition and can be effectively used to display and achieve social standing in the reorganisation of status and class following doi moi.

\section{Mobile distinction}

Material goods play a crucial role in social performance as carriers of messages enabling their owners to communicate social positions, values and traits. They are used in 'cognitive classifications', as put by Douglas and Isherwood (1979) in their classic study The World of Goods. The meaning of goods, however, is fundamentally dependent on context. As Bourdieu $(1984,94)$ reminds us, '[o]bjects, even industrial products, are not objective in the ordinary sense of the word, i.e., independent of the interest and tastes of those who perceive them, and they do not impose the self-evidence of a universal, unanimously approved meaning'. Or in Kopytoff's (1986) terminology, although the world of commodities is indeed marked by homogenisation, the cultural and social 'biographies' of things may differ significantly across societies and cultures. Although automobility seems to represent perhaps the closest we get to a 'global blueprint of modernity' (Hansen, in press), the messages a car conveys must be understood in their context.

Vietnam is a 'transition economy', and the shift from socialism to capitalism has involved an alteration of social hierarchies. At least there is now more room for alternatives to the strict 
hierarchies of the communist party, although connections to the state still represent direct and indirect roads to prosperity (Gainsborough, 2010). Famously, Thorstein Veblen (2007 [1899]) used the concept of 'conspicuous consumption' to explain the purchase of luxury goods for the display of economic power in a new socio-economic context where inherited social positions were losing their monopoly on hierarchically structuring society. Although in a entirely different time and space from Veblen's analysis, this starting point speaks well to the Vietnamese post-doi moi society. Escaping the rather ascetic frames set by the planned economy, the reforms have in many different ways led to a renewed importance of social distinction through consumption (Bélanger, Drummond, and Nguyen-Marshall, 2012; Vann, 2012).

\section{Italian luxury}

In the first decades following doi moi, motorbikes were the ultimate symbol of the new Vietnam, of modernity and progress (Truitt, 2008). While motorbike ownership now has been socially normalised, certain motorbike models are still attached significant status. Driving around Hanoi it is easy to recognise a favourite among the wealthier parts of the young middle-class: the Italian Piaggio or Vespa. All over the city fashion-conscious urbanites are driving around on these Italian icons (see Arvidsson, 2001), and a host of models are available. A representative for Piaggio Vietnam explained in an interview how new market segments have been forming in the country, what she referred to as the premium and luxury markets. These are the segments where Piaggio has been highly successful in Vietnam (see also Wunker, 2011), with the cheapest Piaggio models costing about the double of the cheapest Hondas, and the most expensive, imported models reaching as high as 350 million VND. The Piaggio representative considered the main allure of their scooters not to be quality but style. She further explained how the high-end motorbike market in Vietnam was considered extraordinary, and that they had not been able to achieve the same kind of success in other countries in the region (interview, November, 2013). ${ }^{10}$

The big 'luxury market' for motorbikes is probably partly due to the high taxes imposed on cars, but it is also due to the important position of the motorbike as a means of transportation in Hanoi. The expensive and good-looking Italian motorbikes represent ways to achieve social distinction while keeping the convenience of the motorbike. Importantly, however, many of 
those able to afford the 'luxury' brands of motorbikes also own a car. And as a general symbol of development and modernity, little can now compete with the four-wheeler.

\section{Success on four wheels}

Surprisingly, usually the only small cars you see in the streets of Hanoi are taxis. The private cars predominantly range from normal sedans to very big SUVs ${ }^{11}$. There are many Japanese cars on the roads, particularly Toyotas, but also many BMWs, Audis, Mercedes' and even some Rolls-Royces. It feels slightly absurd to drive in for example the area around the Presidential Palace and the iconic Ho Chi Minh Mausoleum and see these totems of global capitalism move beneath neon signs of the hammer and sickle. At the same time this contradiction is emblematic of Vietnam's 'market socialism'. The cars in the streets of Hanoi indeed reflect Vietnam's successful integration into global capitalism. They also serve as powerful reminders of the fact that some have become very wealthy in the process, and that it is now acceptable to spend very large amounts of money on consumer goods and publically flaunt them.

Cars convey status, wealth and social standing in public spaces better than probably any other commodity. As Wengenroth $(2011,4)$ puts it, as 'the most starkly displayed item of consumption next to clothing, there is no semiotically innocent car'. In a country in rapid development and with immense differences between the richest and the poorest, the symbolic value of the car is arguably even stronger. One of my older informants, a man who had lived in Hanoi most of his life, reflected on the question of why more and more people in Hanoi wanted to get a car instead of - or in addition to - a motorbike. While seeing the car as convenient for escaping bad weather and for taking the family out for trips, he would usually drive his Honda motorbike, and appeared rather annoyed with his high-earning son for buying him a car. He saw the most important reason as related to conspicuous display of wealth:

In my family everyone has a motorbike, but my son still wanted to buy a car. So it's just the Vietnamese characteristic. We want to prove that with a car we are richer. Actually we don't use it to work, we only use it once a week on average. But we still buy it to show other people, it's important (Interview, October 2013, translated from Vietnamese). 
While this tendency is certainly not limited to Vietnamese people, it does reflect a sentiment that is often expressed about the inhabitants of Hanoi. Interestingly, as indeed highlighted by many of my informants, the capital of Vietnam and the home to the communist political elite is famous in Vietnam for a marked tendency towards purchase and display of positional goods, much more so than the financial capital Ho Chi Minh City in the South (see also Fforde $2003)^{12}$.

Since the car is very expensive in Vietnam, it is a clear display of purchasing power. It is also a mobile display, allowing its user to openly show his or her status in the streets. Owning a car today, in the new, capitalist economy of Vietnam, communicates success; that its owner is one of those who have been able to make his or her way in the treacherous, yet potentially extremely lucrative, waters of the market economy. In Hanoi, I was often told in English that the car 'gives you a nice face'. It 'polishes one's name' (danh bong ten tuoi) following a popular Vietnamese phrase. This can have direct implications for its owner.

\section{Better service, higher bribes}

In the system of commodity-based social classifications, a car really makes its driver stand out in the crowd. The messages conveyed by a car in contemporary Hanoi can indeed directly affect the treatment of its owner in social settings. As reflected in this conversation with a young, female car owner, the social impact of driving a car in Hanoi extends beyond just making an impression:

Informant: I think people tend to respect the people driving cars. I think so.

Researcher: Why, do you think?

Informant: Here in Vietnam? Because cars represent your wealth. That kind of thing. So if you go by car, people will think OK, you are rich, you have money, and...And if you go to some kind of service, business, they will treat you better.

Researcher: Yeah? Did you experience this yourself?

Informant: Yes.

Researcher: Like in a restaurant?

Informant: Yeah, yeah! It's different from when I go by motorbike.

(Interview, October, 2013) 
But the message of wealth the car sends does not necessarily lead to positive outcomes for the driver. The prolific traffic police are also able to apply this information to their own specific take on progressive taxation. Thus, my car-owning informants reported that the fines (bribes) they had to pay to the police were often more than twice as high in a car compared to on a motorbike. ${ }^{13}$ Similarly, several informants also told me that shopping alongside the road became more expensive in a car than on a motorbike. The point remains that driving a car in the sea of motorbikes assures different treatment, usually in a positive sense. Nowhere is this as important as for those trying to make a living in the highly relationship-contingent market economy of Vietnam.

\section{The car as a business strategy}

Businessmen in Hanoi today actively use their car to show actual or potential business partners that they can be trusted as successful entrepreneurs. I interviewed one young Hanoian businessman who had recently changed his practical family car towards a more expensive and less practical model. He told me: 'If I have a meeting or appointment with [a] customer I have to go by car'. When I asked why, he said 'because...you know... if I go by car maybe my image is better with the customer'. He said if he already had known the client for a long time he could use his motorbike, but if needing to make an impression he needed the car. But a car alone is not sufficient: 'It should be nice, usually it should be [an] expensive car. Like you know the cost is maybe more than 50.000 US Dollar' (Interview, April 2013). Another young businessman told me a similar story, as can be seen in the following conversation:

Researcher: For your job, do you need to show that you have a car?

Informant: A lot.

Researcher: Why?

Informant: It will give your partners confidence in you

Researcher: Does it matter what type of car?

Informant: Yes, it matters. The better the car, the more they believe in you.

Some kinds of cars make very little change. Like Daewoo's Matiz.

Researcher: And what kinds change it a lot?

Informant: Toyota, Mercedes, BMW.

(Interview, May 2013, translated from Vietnamese) 
The young businessman here discusses a status hierarchy of cars. The Matiz is a small car made by the South Korean car manufacturer Daewoo. This is comparatively low-priced and inconspicuous, and thus does not necessarily communicate sufficient success when inserted 'into the lower ranks of a powerful status hierarchy of objects' (Hansen \& Nielsen, 2014, 77). This, along with the overall high cost of buying and owning any type of car, helps explain the prevalence of luxury cars in the streets of Hanoi.

The statements by these young businessmen were confirmed in many other interviews. What they are discussing is a form of conspicuous consumption, but perhaps more accurately strategies of distinction (Bourdieu, 1984). Social distinction, however, is a tricky game. The high educated part of the elite in Hanoi frowns upon the flaunting of luxury cars as vulgar public display of wealth, something belonging to the nouveau riche. ${ }^{14}$ As an older and highly successful businessman told me, this is something 'rich peasants' do. Of course you can own a car (he did not, he would be driven in company cars or taxis everywhere), but you should not try to 'show off' with it (Interview, October 2013). Nevertheless, in the market economy the car is actively used as an artefact to define, display and entrench positions as successful businessmen. The car in other words assists both spatial and social mobility. This point can be further illustrated by taking a short detour out of the city.

\section{Bringing success to the que}

The Hanoian middle class is increasingly mobile, leaving the city for work and holidays. Most of my informants would nonetheless principally emphasise the importance of one particular mobile practice: returning to the que, the rural hometown. In the context of rapid urbanisation, a large proportion of Hanoi's inhabitants have at some point migrated from the countryside, and return to the que for tet (Lunar New Year) or other special occasions such as deathanniversaries. Returning 'home' is of course a common practice for rural-urban migrants around the world, but through the importance attached to place in Vietnamese identity, belief systems and family life, interlinked with the central position of spatially determined rituals of ancestor veneration, the practice takes on particular significance in Vietnam. With doi moi, as Jellema $(2007,60)$ puts it, 'improved transportation and more disposable income, combined with the relaxation of central control [...], has meant both more mobility away from native places as well as greater ease in return journeys'. 
The car has become increasingly central to returning 'home'. When you get outside the central areas of Hanoi, the streetscapes and motorscapes change character. Motorbikes are still everywhere, but there are more cars and larger vehicles on the roads. The velocity of traffic is much higher and the 'chaos' of the crowded streets of Hanoi change to dangerous high-speed driving practices. The motorbikes are here outside their dominant realm, the unprotected drivers highly exposed to accidents. While there are ample opportunities for leaving the city by public transport networks, the possibility of comfortably leaving the city for short and long trips without relying on public transport (or on renting a car) was highlighted by many of my informants as one of the main attractions of purchasing a car. Furthermore, while it is possible, and indeed increasingly popular among young people to leave Hanoi on a motorbike, it is hardly comfortable to drive long distances on the small vehicles. Particularly for long-distance spatial mobility, the car offers promises of comfort and safety where the two-wheeler cannot compete (Hansen, 2015b). But again, the car is simultaneously a vehicle for and symbol of social mobility.

Coming from a poor province in the North of Vietnam, a young businessman I interviewed spoke of the experience of coming home with a new car. He said in his hometown no one had ever owned one (as an example of the disparities between rural and urban Vietnam), so when he arrived in his car children would come running after him, and all the neighbours would come to visit his family. I first took this as interest in the car as a material object, but he explained that the neighbours did not care too much about the car as such. They came to see him, to try to understand what he had done to be able to afford the car. In this way, he made his family proud, and securely cemented his position in the que as a successful young man. In his own words, 'The car is the best symbol of a successful person. You can rent an apartment, but you have to own a car to show your personality' (Interview, May 2013, translated from Vietnamese). In other words, a motorbike, or even a rented car, could not have delivered the same social benefits as a private car did, and having a nice apartment in the city would mean little when returning to the countryside. The young man had become part of the urban middle class, and was able to use the most obvious proof of his new societal position to travel to his home town.

\section{Mobile pragmatism and conspicuous immobility}

As the discussion so far has shown, the spatial mobility of cars is in many ways central to the social meaning attached to them. They are conspicuous in traffic, and they can be driven to 
the hometown, to business meetings, to restaurants or other public spaces. However, cars are obviously often immobile. Big parts of their 'lives' they are parked. But this device designed for moving people around can also serve a purpose without leaving its allotted parking space. Indeed, one of the most frequent stories I heard in Hanoi when asking people about cars referred to immobility rather than mobility. It was explained to me how some rich people would purchase cars they seldom or never used. According to these stories people buy cars just because car ownership has become expected in certain social positions, or because they want to show that they can buy a car. According to a young businessman in Hanoi, 'they get a car to show their personality, but when they go outside they use a motorbike' (Interview, May, 2013, translated from Vietnamese). In other words, the motorbike is often seen as superior to cars in terms of getting from A to B within the city, and very few of my car-owning informants would stop driving motorbikes. This reflects a sort of mobile pragmatism that I am yet to encounter in accounts of middle-class mobility in other Asian countries, where cars have taken over completely as the preferred means of transportation (e.g. Fischer, 2014 on Malaysia; Nielsen and Wilhite, 2015 on India; Gerth, 2016 on China). Mobile pragmatism notwithstanding, in Hanoi cars have such strong connotations attached to them that they do not even have to be in use to serve their social purpose. Interestingly, this position has also opened for a curious integration of traditional beliefs into practices of mobile distinction.

\section{Conspicuous luck}

For those wanting to stand out further from the crowd in Hanoi than they already do by driving an expensive car, the license plate is a good place to start. In the streets of Hanoi, the license plates of vehicles tell stories about their owners. First of all, the colour of the license plate: If it is red, the vehicle belongs to the military; if blue, it belongs to the public sector; and if white, it is privately owned. But more interestingly, the combination of numbers on the license plate takes on meaning. A license plate with for example the number 8888 guarantees that the owner is a person with significant wealth and political connections.

The combination of the prevalence of accidents and the high economic and emotional value attached to cars has opened for the movement of traditional practices of phong thuy, or feng shui, into traffic, with many car owners for example looking to find a car with a colour that 'matches their personality'. Similarly, the combination of search for luck and distinction has introduced numerology to the streets. In many parts of East and Southeast Asia numbers are believed to have the capacity to bring luck and prosperity as well as bad luck and suffering. In 
the market economy, 'lucky numbers' (so dep in Vietnamese, literally meaning beautiful number) have been commodified, and for example the market for lucky mobile phone numbers is thriving. Also for license plates for cars, numbers are given high financial value. There is a wide variety of numbers that are sought after, and to an outsider the practice can be quite confusing. ${ }^{15}$ In general, eight and nine are positive numbers. Eight in Sino-Vietnamese is bat, which sounds like phat in Vietnamese (meaning development or progress). Nine in Sino-Vietnamese is сии and today means everlasting, permanent, or longevity. On the other hand, the number four symbolizes death. A wide range of number combinations can be positive or negative. For example, it is considered lucky if the numbers are increasing exponentially, or if they in combination add up to eight or nine.

In contrast to mobile phone numbers, it is now illegal to buy lucky numbers for license plates. They are all randomly drawn by pushing a button at the registration office and a number appears on the screen. Still, as in basically any aspect of post-doi moi Vietnam, those with strong financial means and political connections find ways of getting around the system, something that was explained to me in detail by a car retailer (Interview, April, 2013). The inaccessibility of lucky numbers in turn makes them perfect status symbol as only the very wealthy and powerful can get access. As put by Nguyen Truong Quy (2014: 92-93), '[a] truly classy car in Hanoi [...] must have an exclusive license plate number [...] for giving our cars that last, crucial touch of prestige'. There is no fixed price for a good number, but it is a wellknown fact in Hanoi that prices can be very high. When I asked what it would cost to get the number 8888, the 'luckiest' it gets, a young businessman told me: 'Too expensive! One billion Vietnamese Dong. When people see the number plate they can image the owner of the car. No need to talk more.' (Interview, April 2013; see also Gerth, 2016 on license plates in China). Another interesting aspect of these conspicuous practices of numerology is that my informants generally saw it as funny to consider investing in a lucky license plate for their motorbikes. While some still do, this was not considered as a particularly status-enhancing practice. This serves as another example of the declining position of the motorbike in the status hierarchy of goods.

Based on the above discussion it is safe to conclude that in the hierarchy of material objects the private car has clearly overtaken the throne of the motorbike as a sign of success in contemporary Hanoi. This reflects important macro-level changes in Vietnam. While motorbike ownership quickly became fairly uncontroversial, owning a car is more conspicuous, and has not always had positive connotations in Vietnam. As Broz and Habeck 
(2015) note concerning the dual role of cars in the Soviet Union, cars can be seen as suspicious items related to individualism and consumerism rather than socialist progress (see also Siegelbaum, 2008). Indeed, the changing social position of cars can in many ways be seen as a symbol of Vietnam's transition to capitalism.

\section{Normalising automobility: Cars, capitalism, and socio-politically embedded mobility}

In the streets of central Hanoi the system of moto-mobility continues making cars a slow and inconvenient means of transportation. Outside central areas, however, new forms of dwelling, shopping, and moving around are materialising, where the expectation of car ownership is built into the wider roads, bigger supermarkets and extensive spaces for parking (see Hoai Anh Tranh, 2015). Likewise, new highways are often only accessible for cars, creating a new form of socio-spatial separation between car drivers and motorbike drivers. These changes in mobility regimes reflect larger development trends in Vietnam.

As is typical for contemporary capitalism and indeed for Vietnam's development experience in general, the motorbikes and cars on the roads in Hanoi are manufactured by big actors from more mature capitalist economies. They are in many ways 'global capitalism on wheels', represented through different Asian and Italian motorbike brands and East-Asian, European or American car brands. The new flows of goods associated with doi moi have been fundamental to the development of the current motorscape in Vietnam (Hansen, 2015b). But the reforms involved much more than spatial movement of goods, they have indeed led to a renegotiation of the role of goods and private consumption in the development project of the country.

Communist planned economies have always, in different ways and through different means, restricted consumption alongside a promise of future material affluence. This restriction usually goes along well with an ideological scepticism towards what is considered bourgeoisie high levels of individual consumption. In a society where everyone is supposed to be equal, display of personal wealth can be dangerous. Although there were certainly very different levels of wealth during the communist times in Vietnam (see for example Truitt, 2013), one had to be careful with conspicuous display of relative affluence. This changed with transition, but just as reforms were gradual this was also a gradual process. The need for growth in the new economic system, as Vann (2012) has pointed out, led to a shift in state rhetoric towards valuing even conspicuous display of wealth as positive for the economy and 
thus for Vietnam's overall vision and goal of modernisation and industrialisation. In acts that just a few decades ago would be materially impossible (due to the unavailability of goods) and socially disastrous, the Hanoian upper and middle classes today openly display their wealth through housing, clothing, eating practices and, as Jellema (2007) points out, even religious worship. Nowhere, however, is the newly acquired wealth more visible than in traffic. As Truitt $(2008$, p. 4) puts it, in Vietnam 'it is in traffic that one sees the emergence of the middle class'.

These changes were reflected by one of my older informants, a high-ranking public sector employee who bought a car in the early 2000s, at a time when very few people had cars in Hanoi: 'In my office, I was maybe one of the first to use a private car. When people saw me buying a car, they also bought one. Even if they had enough money, they were afraid of buying a car until I got one'. I asked him why they were afraid, and he said 'because they are in charge of a position, people see them and may get the wrong impression. This gradually disappears. That's in the past, not now. Now people are afraid of buying cars for other reasons'. People are now rather worried about the high costs, the difficulties of driving in Hanoi and the strict traffic rule enforcement as well as lack of available parking space, he continued (Interview, April 2013, translated from Vietnamese). While there are still government-induced disincentives to buying cars through high taxes, these are not ideologically driven, but rather pragmatic approaches to raise public funds as well as to a serious development challenge driven by the inability of the streets of Vietnamese cities to accommodate widespread car ownership (Hansen, in press).

Thus, cars now being materially and (for some) financially available and socially and politically acceptable, car ownership is increasing fast in Hanoi. Alongside this trend, the car seems to be gradually losing its position as an extraordinary commodity. Like motorbikes before them, cars are increasingly normalised. In the words of a car retailer in Hanoi, 'the car is still a form of jewellery in Vietnam, but it is gradually changing towards a means of transportation' (Interview, April 2013). While the car is still an elusive dream for many, it is already seen as mundane for the better off in Vietnam. In a discussion with a group of businessmen, I was told that the car does no longer work as a display of success, since 'everyone has one' (Interview, May 2013). With Hanoi's 36 cars per 1000 people (World Bank, 2014a) this is mildly put an overstatement. Yet, it is a telling example of how cars have achieved a position where certain occupations and classes come with an expectation of four- 
wheeled mobility. This normalisation process may in turn pave the way for a potential break with the system of moto-mobility.

\section{Between the exceptional and the expected}

History has shown that a gradual increase in levels of car ownership can be expected with increasing affluence (Medlock and Soligo, 2002), so in that sense the gradual normalisation of automobility in Hanoi is to be expected. In many East and Southeast Asian countries widespread motorbike ownership has been common. Good comparative numbers on motorbikes are hard to find, but Vietnam certainly does have a very high ratio of motorbike ownership. For example Thailand, also known for significant levels of moto-mobility, in 2000 had about 215 motorbikes per 1000 people (Nagai et al. 2003), a time when Thailand's GDP per capita was closer to that of Vietnam today. In Vietnam, with around 43 million motorbikes and a population of approximately 92 million, the rate is currently around 470 motorbikes per 1000 people, in Hanoi and Ho Chi Minh City as high as 610 and 700 motorbikes per 1000 people respectively (World Bank 2014a).

But also in countries with high prevalence of motorbikes, car ownership has increased rapidly with economic growth (Jakapong and Chumnong, 2010; Nishitateno and Burke, 2014), although to different extents. A look at so-called 'motorisation rates' (four-wheel vehicles per 1000 people) shows that Vietnam's motorisation rate of 21 is significantly lower than other 'emerging economies' in the larger region, for example Indonesia's 77, China's 91, Thailand's 208 and Malaysia's 397 (OICA, 2014, numbers from 2013). We cannot conclude much based on these numbers, however, since compared to these countries Vietnam is still relatively poor. ${ }^{16}$ These countries also have in common relatively large domestic automobile industries, and for example Malaysia and China have actively encouraged domestic car consumption (Barter, 2004; Gerth, 2016). The Vietnamese government has attempted to develop a domestic auto industry, but so far has placed high taxes and fees on domestic car consumption (this may be changing, see Minh Hung, 2015). Different ministries disagree on how to deal with the car, but as Vietnam prepares to open its borders to imports from other Southeast Asian car manufacturers car ownership may increase even more rapidly in the future (Hansen, in press). 
However, economic explanations can only take us part of the way. Mobility and its cultures, practices, meanings and moorings, and along with this the processes that entrench motomobility and automobility in different countries and societies, are complex and contextspecific. As Sheller and Urry $(2006,210)$ put it, '[m]obility is always located and materialised'. This paper has analysed the mobile particularities of Hanoi, and in order to draw good comparisons more research is needed on Asian and Southeast Asian mobilities; both on the spread of automobility and on the importance of moto-mobility.

\section{Conclusions}

It is due time for mobilities research to appreciate the motorbike as a crucial part of everyday mobility for a large portion of the world's inhabitants. This, combined with deeper engagement with the meanings, moorings and expansion of automobility in different countries, cultures and societies could lead to interesting theoretical discussions. This paper has suggested that the best way of doing so is through strong empirical grounding in the places and spaces in question.

As this paper has shown, there are many particularities to motorised mobility in Hanoi. The motorbike, for now at least, remains the king of the road, and the streetscapes and urban geographies of the city are strongly shaped by the system of moto-mobility. This system already delivers on many of the promises associated with cars in the literature on automobility. Motorbikes provide flexibility, individual movement, and relatively effortless spatial mobility. Cars are nevertheless increasing in number and have overtaken the position of motorbikes as aspirational and positional goods. In Hanoi, after years of motorbike dominance, there is currently a craze for cars that extends beyond the functional appeal of the four-wheeler and that has seen car ownership emerge as a personal development goal for many.

Conspicuous display of often immense wealth has become acceptable in Vietnam's 'market socialism', and rich children of communist leaders driving luxury capitalist-produced cars are emblematic of the contradictions embedded in Vietnam's development model. As a particularly stark contrast to the closed borders of the days of the planned economy, global capitalism is vividly represented in the streets of Hanoi through Japanese, Korean, German, French and American cars. Some of them cost more than a lifetime's earning for the 
Vietnamese working class, and thus also act as a reminder of the inequalities embedded in the new economy.

Both in general social performance and in business strategies the car is now the ultimate object for displaying and achieving upward social mobility in the market economy. This seems to be diminishing as car ownership becomes more widespread, but for now the car effectively separates, both mentally and physically, the richest from the rest in Vietnam. To conclude that people consume cars only to display status would however be ungrounded, as the car clearly also possesses unique functional value. Rather mobile distinction is one important factor for explaining the allure of cars in a city already on wheels. Driving a car is a very different experience than driving a motorbike, and as car ownership spreads the comfort, cleanliness and relative safety promised by the four-wheeler seems to become embedded in the expectations of higher material living standards. For the sake of urban mobility, the social position of cars may well signal a new era and the beginning of a break with the dominance of two-wheeled transport.

The position of the car in Vietnam's development strategies is still a contested topic. In the streets of Hanoi, however, cars are predominantly discussed as a manifestation of progress and development. Indeed, many of my informants referred to an alteration of a traditional Vietnamese proverb describing what a young man should aspire to achieve in life; 'buy a buffalo, build a house, get a wife' has now become 'buy a car, build a house, get a wife'. The remaining question is to what extent the system of moto-mobility will slow down the speed of increasing car ownership.

\section{Acknowledgement}

I am grateful for the comments made on earlier versions of this paper by Hege Merete Knutsen, Harold Wilhite, Desmond McNeill, Ida Rudolfsen, Karina Standal, and Maren Aase, as well as by the anonymous referees. 


\section{Notes}

${ }^{1}$ As is common practice in Vietnam, I use the term motorbike to refer to most two-wheelers, although I use 'motorcycle' when discussing vehicles with large engines. Most motorbikes in Vietnam range between 50 and $150 C C$, and many of them would elsewhere be known as scooters.

${ }^{2}$ The reforms saw Vietnam turn away from the planned economy towards what is officially known as a 'market economy with socialist orientation' (Masina, 2006; Beresford, 2008), what (Hansen, 2015a: 96) suggests could more accurately be described as 'state capitalism with a Leninist orientation'. The changes following reforms have involved very high levels of economic growth and impressive poverty reduction, as well as rapid urbanisation, rapidly growing levels of private consumption, and significant social inequalities. While poverty is still prevalent and particularly so in rural areas, urban middle and upper classes have emerged with significant purchasing power (Bélanger, Drummond, and Nguyen-Marshall, 2012).

${ }^{3}$ While there has been some research on the motorcycle industry (Fujita, 2013; Intarakumnerd and Fujita, 2008) and some on the attempts to develop the domestic automobile industry (Sturgeon, 1998; Hansen, in press), very little has been done on motorised mobility in Vietnam (see Truitt, 2008 and Hansen, 2015b for exceptions). ${ }^{4}$ While driving in Hanoi was an overall pleasurable experience, it also involved exposure to high levels of air pollution and involvement in several almost-accidents.

${ }^{5}$ The global motorbike market is indeed expanding. However, I am not convinced that considering any of these systems as self-expanding is a very helpful starting point. As any other commodity, cars and motorbikes depend on systems of provision, institutional arrangements and flows of goods. There is a complex range of agents involved in global and local mobilities, from individual users to large manufacturers, with local and national governments as strong mediators.

${ }^{6}$ See Hansen (2015b) for a discussion of the dialectical relationship between infrastructure and two-wheeled mobility in Hanoi.

${ }^{7}$ By the time of writing, 22.000 VND = approximately 1 US Dollar.

${ }^{8}$ The police was a popular topic in my interviews. Almost all of my informants had at some point in their lives been stopped by the police, and there was general agreement that if you are unlucky the police will always find a reason to fine you. The practice for fines is that the police will often take your motorbike until you have been to the police station to pay the fine. As getting by without the motorbike is a little tempting scenario for most Hanoians, the problem is usually solved through direct payment to the police officer.

${ }^{9}$ In contrast to regular taxis, a xe om traditionally does not operate with meters or fixed prices. A new invention, however, are metered motorbike taxis and motorbike taxi services specialized at taking children to school. See also Sopranzetti (2014) for an interesting discussion of the social and political roles of motorbike taxis in Thailand

${ }^{10}$ Indeed, Piaggio has established Vietnam as its manufacturing base for Southeast Asia.

${ }^{11}$ In all my prying about cars, the prevalence of big cars was either explained as a status symbol or by the fact that the roads outside the city are often in a very bad condition (reinforcing the point that driving long distance is an important reason for Hanoians to buy cars).

${ }^{12}$ While I do not have a convincing explanation for this phenomenon, at least part of the answer may be found in a traditionally stronger focus on status and prestige in the former communist capital versus the more liberal southern parts of the country with their relatively short and shallower experience with communism and historically stronger presence of foreign consumer goods. Many of my informants referred to people in the South as 'more relaxed'.

${ }^{13}$ Interestingly, informants explained to me that if the car looks particularly luxurious, perhaps even with a conspicuous license plate, the police would usually not stop it. Although a very expensive car could signify a profitable 'client', it also means that its driver probably has very powerful political connections.

${ }^{14}$ Arguably no one is 'old rich' in Hanoi, but there are significant differences between those highly educated and politically connected, and those mainly possessing newly acquired economic capital (see Huong Le Thu, 2015 for a recent discussion on class categorization in Vietnam).

${ }^{15}$ This is a topic that sparked much discussion in my interviews. While opinions varied as to the importance of lucky numbers, even those seeing the practice as rather 'silly superstition' would normally prefer a nice number for their license plate.

${ }^{16}$ According to World Bank (2015) data, Vietnam's GNI per capita in 2014 was USD 1890. By contrast, Indonesia's GNI per capita was twice as high (USD 3630), Thailand's almost three times as high (USD 5370), China's almost four times as high (USD 7380), and Malaysia's more than five times as high (USD 10.760). 
Vietnam's GNI per capita was slightly higher than India (USD 1570), which by comparison in 2013 had a motorisation rate of 20 (OICA, 2014). 


\section{References}

Adey, P. 2008. "Aeromobilities: Geographies, Subjects and Vision." Geography Compass 2 (5): 13181336.

Aldred, R. and Jungnickel, K. 2013. "Matter in or out of place? Bicycle parking strategies and their effects on people, practice and places." Social \& Cultural Geography 14 (6): 604-624.

Appadurai, A. 1986. "Introduction: commodities and the politics of value." In The Social life of things: commodities in cultural perspective, edited by Appadurai, A. Cambridge: Cambridge University Press.

Arvidsson, A. 2001. "From Counterculture to Consumer Culture: Vespa and the Italian youth market, 1958-78." Journal of Consumer Culture, 1 (1): 47-71.

Barter, P. 2004. "Transport, urban structure and lock-in in the Kuala Lumpur Metropolitan Area." International Development Planning Review, 26 (1): 1-24.

Bélanger, D., Drummond, L. B. W. and Nguyen-Marshall, V. 2012 "Introduction: Who Are the Urban Middle Class in Vietnam?" In The Reinvention of Distinction: Modernity and the Middle Class in Urban Vietnam, edited by Nguyen-Marshall, V., Drummond, L. B. W. and Bélanger, D., 1-17. Dordrecht: Springer.

Beresford, M. 2008. "Doi Moi in review: The challenges of building market socialism in Vietnam." Journal of Contemporary Asia 38 (2): 221-243.

Bourdieu, P. 1984. Distinction : a social critique of the judgement of taste. London: Routledge \& Kegan Paul.

Broz, L. and Habeck, J. O. 2015. "Siberian Automobility Boom: From the Joy of Destination to the Joy of Driving There." Mobilities 10 (4): 552-570.

Butler, G. and Hannam, K. 2014. "Performing Expatriate Mobilities in Kuala Lumpur." Mobilities 9 (1): $1-20$.

Büscher, M., Urry, J. and Witchger, K.(2011. "Introduction: Mobile Methods." In Mobile Methods, edited by Büscher, M., Urry, J. and Witchger, K. 1-19. London: Routledge.

Cerise, E. and Maximy, R. d. 2010. "Road System and Urban Recomposition in Hanoi." In The Vietnamese City in Transition, edited by Gubry, P., Castiglioni, F., Cusset, J.-M., Thieng, N. T. and Huong, P. T. 33-62. Singapore: ISEAS.

Cresswell, T. 2006. On the Move: Mobility in the Modern Western World. London: Routledge.

Cresswell, T. 2010. “Mobilities I: Catching up.” Progress in Human Geography 35 (4): 550-8.

Cresswell, T. 2012. “Mobilities II: Still.” Progress in Human Geography 36 (5): 645-53.

Cresswell, T. 2014. “Mobilities III: Moving on." Progress in Human Geography 38 (5): 712-21.

Dennis, K. and Urry, J. 2009. After the car. Cambridge: Polity.

Douglas, M. and Isherwood, B. 1979. The world of goods. New York: Basic Books. 
Drummond, L. B. W. 2012. “Middle Class Landscapes in a Transforming City: Hanoi in the 21st Century." In The Reinvention of Distinction: Modernity and the Middle Class in Urban Vietnam, edited by Nguyen-Marshall, V., Drummond, , L. B. W. and Bélanger, D. Dordrecht: Springer.

Edensor, T. 2004. "Automobility and National identity: Representation, Geography and Driving Practice." Theory, Culture \& Society, 21 (4/5), 101-120.

Featherstone, M. 2004. "Automobilities: An Introduction." Theory, Culture \& Society 21 (4-5): 1-24.

Fforde, A. 2003. "Vietnam - culture and economy: dyed-in-the-wool tigers?" In Consuming Urban Culture in Contemporary Vietnam, edited by Drummond, L. B. W. and Thomas, M. 35-59. London: RoutledgeCurzon.

Fischer, J. 2014. "Islamic mobility: Car culture in modern Malaysia." Journal of Consumer Culture, doi: $10.1177 / 1469540514531683$.

Fujita, M. 2013. "The Rise of Local Assemblers in the Vietnamese Motorcycle Industry: The Dynamics and Diversity of Industrial Organization." In Vietnam's economic entities in transition, edited by Sakata, S. 146-166. Basingstoke: Palgrave Macmillan.

Gainsborough, M. 2010. Vietnam: rethinking the state. Zed Books, London.

Gerth, K. 2016. "Driven to Change: The Chinese State-Led Development of a Car Culture and Economy". In Energy and Transport in Green Transition: Perspectives on Ecomodernity, edited by A. Midttun, A. and Witoszek, N. London: Routledge.

Gillen, J. 2015. "Streets of fire: motorbike mobilities in Vietnam". Area, doi:10.1111/area.12225

Giucci, G. 2012. The Cultural Life of the Automobile: Roads to Modernity. Austin: University of Texas Press.

GSO - General Statistics Office of Vietnam. 2012. Statistical Yearbook, Hanoi: Statistical Publishing House.

Hansen, A. 2015a. "The best of both worlds? The power and pitfalls of Vietnam's development model." In Emerging Economies and Challenges to Sustainability: Theories, Strategies, Local Realities, edited by Hansen, A. and Wethal, U. 92-105. London and New York: Routledge.

Hansen, A. 2015b. "Transport in transition: Doi moi and the consumption of cars and motorbikes in Hanoi." Journal of Consumer Culture. doi: 10.1177/1469540515602301.

Hansen, A. In press. "Driving development? The problems and promises of the car in Vietnam." Journal of Contemporary Asia.

Hansen, A. and Nielsen, K. B. 2014. "Cars of Future Past in Vietnam and India." Tvergastein 4: 72-79.

Hansen, A., Nielsen, K.B. and Wilhite, Harold. In press. "Staying Cool, Looking Good, Moving Around: Consumption, Sustainability and the 'Rise of the South'", Forum for Development Studies.

Hoai Anh Tran. 2015. "Urban Spaces Production in Transition: The Cases of the New Urban Areas of Hanoi." Urban Policy and Research, 33 (1): 79-97. 
Huong Le Thu. 2015. "The Middle Class in Hanoi: Vulnerability and Concerns." ISEAS Perspective \# 8. Singapore: ISEAS.

Intarakumnerd, P. and Fujita, M. 2008. "Coping with a Giant: Challenges and Opportunities for Thai and Vietnamese Motorcycle Industry from China." Science, Technology \& Society 13 (1): 35-60.

Jakapong Pongthanaisawan and Chumnong Sorapipatana. 2010. "Relationship between level of economic development and motorcycle and car ownerships and their impacts on fuel consumption and greenhouse gas emission in Thailand. Renewable and Sustainable Energy Reviews, 14 (9): 29662975.

Jellema, K. 2007. "Returning Home: Ancestor Veneration and the Nationalism of Doi Moi Vietnam." In Modernity and Re-enchantment: Religion in Post-revolutionary Vietnam, edited by Taylor, P. 57-89. Singapore: Institute of Southeast Asian Studies.

Kopytoff, I. 1986. "The cultural biography of things: commoditization as process." In The Social life of things: commodities in cultural perspective, edited by Appadurai, A. Cambridge: Cambridge University Press.

Laurier, E., Lorimer, H., Brown, B., Jones, O., Juhlin, O., Noble, A., Perry, M. et al. 2008. “Driving and 'Passengering': Notes on the Ordinary Organization of Car Travel." Mobilities 3 (1): 1-23.

Leather, J., Fabian, H., Gota, S. and Mejia, A. 2011. "Walkability and Pedestrian Facilities in Asian Cities: State and Issues", in ADB Sustainable Development Working Paper Series, edited by Asian Development Bank. Asian Development Bank, Manila, Philippines.

Mai Ha. 2014. "Vietnam to recognize international driver's license in 2015." Thanh Nien News, http://www.thanhniennews.com/society/vietnam-to-recognize-international-drivers-license-in2015-33942.html (Date: 27.11.2015).

Masina, P. P. 2006. Vietnam's development strategies. Oxon: Routledge

Mcllvenny, P. 2015. "The Joy of Biking Together: Sharing Everyday Experiences of Vélomobility." Mobilities 10 (1): 55-82.

Medlock, K. B. and Soligo, R. 2002. "Car Ownership and Economic Development with Forecasts to the Year 2015". Journal of Transport Economics and Policy, 36 (2): 163-188.

Merriman, P. 2014. “Rethinking Mobile Methods." Mobilities 9 (2): 167-187.

Merriman, P. 2009. "Automobility and the Geographies of the Car." Geography Compass 3 (2): 586599.

Middleton, J. 2011. "Walking the City: The Geographies of Everyday Pedestrian Practices.", Geography Compass 5 (2): 90-105.

Minh Hung. 2015. "Vietnam, the nation of motorbikes, may soon see a car boom." Thanh Nien News, http://www.thanhniennews.com/commentaries/vietnam-the-nation-of-motorbikes-maysoon-see-a-car-boom-52953.html (Date: 27.11.2015).

MONRE - Ministry of Environment and Natural Resources, Socialist Republic of Vietnam. 2007. National State of Environment 2007. Hanoi: MONRE. 
Monroe, K. V. 2014. "Automobility and Citizenship in Interwar Lebanon." Comparative Studies of South Asia, Africa and the Middle East, 34 (3): 518-531.

Nagai, Y., Okada, Y., Fukuda, A., and Hashino, Y. 2003. "Two-wheeled Vehicle Ownership Trends and Issues in the Asian Region". Journal of the Eastern Asia Society for Transportation Studies, 5: 135-146.

Nguyen Truong Quy. 2014. The Wandering Motorbike [Xe máy tiếu ngạo], translated by Jacob 0. Gold, Ann Arbor: Center for Southeast Asian Studies.

Nielsen, K. B., and Wilhite, H. 2015. „The rise and fall of the 'people's car': middle-class aspirations, status and mobile symbolism in 'New India'." Contemporary South Asia.

doi:10.1080/09584935.2015.1090951

Nishitateno, S. and Burke, P. J. 2014. "The motorcycle Kuznets curve." Journal of Transport Geography 36: 116-123.

OICA. 2014. World vehicles in use, http://www.oica.net/wp-content/uploads//total-inuse-2013.pdf, (Accessed 03.08.2015)

Pinch, P. and Reimer, S. 2012. "Moto-mobilities: Geographies of the Motorcycle and Motorcyclists." Mobilities 7 (3): 439 - 457.

Roy, S., and Hannam, K. 2013. "Embodying the Mobilities of the Darjeeling Himalayan Railway." Mobilities, 8 (4): 580-594.

Sheller, M. 2004. "Automotive Emotions: Feeling the Car." Theory, Culture \& Society 21 (4-5): 221242.

Sheller, M. and Urry, J. 2000. "The City and the Car." International Journal of Urban and Regional Research 24 (4): 737-757.

Sheller, M. and Urry, J. 2006. "The new mobilities paradigm." Environment and Planning A 38: 207226.

Short, J. R. and Pinet-Peralta, L. M. 2010. "No Accident: Traffic and Pedestrians in the Modern City." Mobilities 5 (1): 41-59.

Siegelbaum, L. H. 2008. Cars for Comrades: The Life of the Soviet Automobile. Ithaca: Cornell University Press.

Sopranzetti, C. 2014. "Owners of the Map: Mobility and Mobilization amd Motorcycle Taxi Drivers in Bangkok." City \& Society 26 (1): 120-143.

Sturgeon, T. J. 1998. The Automotive Industry in Vietnam: Prospects for Development in a Globalizing Economy. Report Prepared for Development Strategy Instiute, Ministry of Planning and Investment.

Thanh Nien News. 2014. Hanoi to kick out unlicensed taxis.

http://www.thanhniennews.com/society/hanoi-to-kick-out-unlicensed-taxis-29858.html (accessed 02.09.15) 
Thrift, N. 2004. "Driving in the City." Theory, Culture \& Society 21 (4-5): 41-59.

Truitt, A. 2008. "On the back of a motorbike: Middle-class mobility in Ho Chi Minh City, Vietnam." American Ethnologist 35 (1): 3-19.

Truitt, A. 2013. Dreaming of Money in Ho Chi Minh City. Seattle and London: University of Washington Press.

Tuoi Tre News. 2015. Vietnam to start checking motorbike emissions in 2018, http://tuoitrenews.vn/society/27872/vietnam-to-start-checking-motorbike-emissions-in-2018 (accessed 07.08 2015).

Urry, J. 2004. "The 'System' of Automobility." Theory, Culture \& Society 21 (4-5): 25-39.

Vann, E. F. 2012. "Afterword: Consumption and Middle-Class Subjectivity in Vietnam." In The Reinvention of Distinction: Modernity and the Middle Class in Urban Vietnam, edited by NguyenMarshall, V., Drummond, L. B. W. and Bélanger, D. 157-170. Dordrecht: Springer.

Vannini, P. 2009. Alternative Mobilities: Routes Less Travelled. Farnham: Ashgate.

Veblen, T. 2007 [1899]. The theory of the leisure class : an economic study of institutions. Oxford: Oxford University Press.

Wengenroth, U. 2011. "Automobiles." In Encyclopedia of Consumer Culture, edited by Southerton, D. Thousand Oaks: SAGE. doi: http://dx.doi.org/10.4135/9781412994248.n31

World Bank. 2011. Vietnam Urbanization Review. Hanoi: World Bank.

World Bank. 2014a. "Motorization and urban transport in East Asia: Motorcycle, Motor Scooter \& Motorbike Ownership \& Use in Hanoi." Technical Report No. 1: Context and Scoping. Hanoi: World Bank.

World Bank. 2014b. "Motorization and urban transport in East Asia: Motorcycle, Motor Scooter \& Motorbike Ownership \& Use in Hanoi, Final Report. Hanoi: World Bank.

World Bank. 2015. "2015 World Development Indicators, country profiles", http://databank.worldbank.org/data/Views/Reports/ReportWidgetCustom.aspx?Report Name=Cou ntryProfile\&ld=b450fd57\&tbar=y\&dd=y\&inf=n\&zm=n (accessed 26.11.2015).

Wunker, S. 2011. "How the Vespa became Vietnamese." Forbes.

http://www.forbes.com/sites/stephenwunker/2011/11/08/how-the-vespa-became-vietnamese/ (Date: 27.11.2015). 